Int. J. Curr. Res. Med. Sci. (2017). 3(10): 4-10

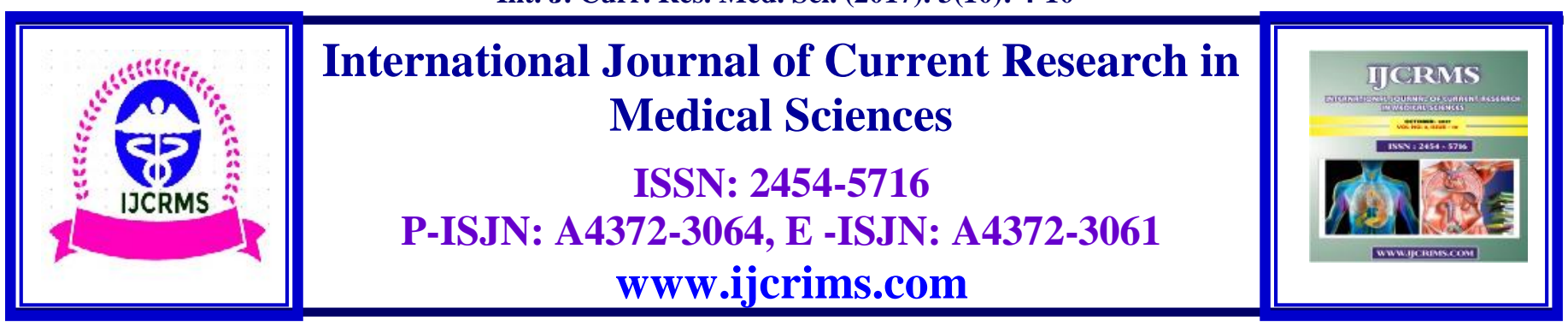

\title{
Exploration and Personification of External therapies in Siddha system of medicine
}

\author{
M.Nagalakshmi ${ }^{1}$, S.Mohamed Ajmal ${ }^{1}$, A.P.Uma ${ }^{2}$. \\ ${ }^{1}$ Final BSMS, Sivaraj Siddha Medical College, Salem-636307. \\ ${ }^{2}$ Department of Sirappu Maruthuvam, Sivaraj Siddha Medical College, Salem-636307.
}

\begin{abstract}
The traditional Dravidian system of medicine referred to popularly as Siddha medicine is a vast repository of external therapies particularly administration of drugs through routes other than oral. These procedures are important in the management of health and disease. Great stress is laid by Siddhars, the promoters of the medical system, on these procedures not only in prevention and cure of diseases but also in promotion of health. The thirty two External therapies include ophthalmic application, nasal application, aural application, Oleation, Steam therapy, Physical manipulation therapies, Heat therapy, Other topical applications, Bone setting, Bloodletting etc. Most of these therapies are aimed at maintaining a healthy balance of three humours [Tridosham] and also the seven tissue types of the body [Sapta dhatus]. Some of the procedures need to be followed at regular frequency as a daily regimen or seasonal regimen to maintain this balance. Maximum efficacy of treatment is achieved by a judicious approach of using external therapies. This is the Hallmark of Siddha Medical Science. External therapies can be done in major measure with locally available resources and therefore is accessible as well as affordable to the entire society.
\end{abstract}

Keywords: Siddha medicine, External therapies, Tridosham, Sapta dhatus.

\section{Introduction}

Siddha Medicine is a vast repository of External therapies. In several instances, only the procedures without any drug are sufficient and these procedures are already systematized. Most of the therapies are aimed at maintaining healthy balance of the three physiological factors and also seven tissues of the body. There are occasions where administration of oral medicines becomes impossible and hence to revive the patient, administration of drugs or manipulation through external therapies like thokkanam, pattru, ottradam are required. Nasal application including inhalation and ophthalmic applications become important particularly in unconscious comatose patients, epilepsy, stroke patients and conditions like trauma, snake bite. It is very clear that the ancient physicians knew the connections between the brain and the sense organs and chose their routes and drugs accordingly [1]. Siddha Medicine is classified as Internal Medicines [Aga Marundugal 32] and External medicines [Pura marundugal 32] $]_{[2]}$. In Siddha system of Medicine, the term "Marundhu" is not exactly equivalent to the English 'drug'. "Marundhu" may be concrete 
or abstract. The abstract may be physical manipulation, heat or cold application, etc., Hence these non oral medicines are listed as External Medicines - 'Puramarundhugal'. External therapy procedures are as important as in the management of Health and Disease. According to the mode of application, the siddha medicines could be categorized into two classes. Aga marunthugal/Internal medicines were used through the oral route and further classified into 32 categories based on their form, methods of preparation, shelf - life, etc., Pura marunthugal/External medicines include certain forms of drugs and also certain applications [such as nasal, eye and ear drops] and also certain procedures [such as leech application]. It is also classified into 32 categories [3].

\section{Materials and Methods}

\subsection{Kattu [Bandage]}

Kattu is applying a strip of materials such as cotton cloth with application of medicine made up of botanicals, inorganic substances [Pashanas] etc. in an affected site [3].

Grind the stem of Cissus quadrangularis [Pirandai], Leaves of Basella alba [Kodipasalai], Tender leaves of Delonix elata [Vatanarayanan], Leaves of Cardiospermum helicacabum [Mudakatran], Seeds of Trachyspermum ammi [Omam] and Resin of Shorea robusta [Kungiliyam] is made into poultice and applied as kattu for Fracture ${ }_{[4]}$.

\subsection{Pattru [Poultice]}

Pattru is the application of paste obtained from plant extract or by grinding raw drug with or without heating them. Normally the medicine to be applied is made into a thick paste and applied over the affected region ${ }_{[1]}$.

Pound the Kaavikkal and sift them. Add the egg white into the Kaavikkal powder and make a fine paste to apply locally for Elephantiasis [4].

\subsection{Poochu [Liquid application]}

Poochu is application of liquid formulation locally. Application of medicated oils or herbal juices or mixtures of powdered drugs [1].

A poultice is made with the root of Acalypha indica [Kuppaimeni], Amaranthus spinosus [Mullukkeerai] and Acorus calamus [Vasambu], added to sesame oil and boiled to prepare oil for the topical application of Carbuncle [5].

\subsection{Kalimbu [Ointment]}

Kalimbu is defined as the buffer of oil and water, compound with specific drug powders.

Terminalia chebula [kadukkai] are powdered, ground with butter and applied over wounds and ulcers [3].

\subsection{Seelai [Medicated gauze]}

This type of external medicine is in the form of medicated plasters. Plasters are prepared by grinding toxic materials in water or herbal juice. A piece of cloth is soaked in this and externally applied over wounds.

Dressings can be impregnated with antiseptic inorganic materials, as in borax [Vengaram] or castor oil was first used in the first surgical dressings [Karaseelai $]_{[3]}$.

\subsection{Varthy [Medicated wick]}

This type of external medicine is in form of medicated wicks. Caustic substances are ground well with herbal juices or decoctions, a piece of cloth is soaked in this and a wick is prepared.

Wicks can be prepared from honey and rock salt [Indhuppu] and inserted into the anal orifice for Purgation [6].

\subsection{Pasai [Cream]}

A semisolid lipid or resin / gum based applications, usually fats are used as bases, vegetable oils or bees wax. As with creams they 
are emollient and protective, but stay on the skin longer [3]. Shells of fresh water mussel are heated on charcoal fire and dropped in the fresh juice of Emblica officinalis [Nellikkai]. The process is repeated for 3-5 times. The ash so obtained is triturated with castor oil till it attains waxy consistency. The ointment is useful in crack foot. Powder of White arsenic [Vellai paadaanam] is added to molten Bees wax and mixed well. This mezhugu is warmed and applied on Abscess and Bubo [7]

\subsection{Kali [Paste]}

Medicinal materials are mixed with rice flour or flour of any cereals or pulses and cooked and applied on the affected site [3].

In case of Abscess, Rice flour and Turmeric are ground well with water, heated, made into paste and applied over it ${ }_{[8]}$.

\subsection{Podi [Powder]}

Powdered minerals and raw herbs are used as dusting powder and is applied over the wounds and Ulcers [3].

Powder of Alpinia officinarum [Sittraratthai] is applied on the vertex after oil bath in infants to prevent the increase of Kapham [3].

\subsection{Neer [Medicated Liquid]}

Raw drugs are soaked in water or made into decoction to concentrate or powerfully potent substances are greatly diluted and used to wash wounds. They are antiseptic solutions. This is prepared by either soaking the raw drugs in water and making a decoction of it or diluting the caustic substances $[3]$.

Decoction of Thiripala used in washing wounds, Eczema and non-healing ulcers. It is also used as gargle in Gingivitis and Oral ulcers. This is also used as douche for washing Uro-genital system, Ano-rectal diseases [3].

\subsection{Nasiyam [Nasal drops]}

It is a process by which the drug is administered through the nostrils. Fresh plants are cleaned thoroughly or blanched, crushed and juice extracted, filtered and instilled into the nostril. Individual oil or herbal juices or flower juices are also used for nasiyam $[3]$.

The leaves of Ocimum sanctum [Kaattu thulasi], Leucas aspera [Thumbai], Vitex negundo [Notchi] shall be crushed individually with normal salt and the juice so obtained is instilled into the nostrils. Nasiyam helps in eliminating the excess kapham and cures Headache, Sinusitis and Chest congestion [9].

\subsection{Naasigabharanam [Insufflation]}

Insufflation is a common route of administration with many respiratory drugs used to treat conditions in the lungs [Asthma or emphysema] and Paranasal sinuses [allergy] [3].

Wild cow dung is soaked in the latex of Calotropis gigantea [Erukku] and dried. This process is repeated for ten times and made into ash by calcinations process. Ash is snuffed into nostril for treating Sinusitis [10].

\subsection{Oodhal [Blowing]}

Some Raw herbal leaves or medicines are chewed by the physician and the aromatic air is blown into the nose or ear of the patient as such or with the use of tools [3].

Vengayam [Allium cepa] is chewed and blown in the eyes of the patient suffering from Exanthematus fever $[6]$.

\subsection{Mai [collyrium]}

Raw drugs is ground with Anjanakkal and leaf juices, it is then prepared into mai or waxy form by adding ghee. Mai is nothing but collyrium for the eyes [3]. 
Equal quantities of the following materials are powdered separately and triturated with lime juice and rolled into pills, shade dried and stored Zingiber officinale [Chukku], Piper longum [Thippili], Rock salt [Indhuppu], Allium sativum [Vellai poondu], Barringtonia acutangula [Samuthrapazham], Acorus calamus [Vasambu]. This pill is rubbed with the lime juice and applied as a Collyrium for treating convulsions as seen in Tetanus [11].

\subsection{Kalikkam [Eye drops]}

Application of eye drops is called as Kalikkam. It is either applied in the form of herbal juices or by dissolving the medicated pills in honey [3].

Dry Zingiber officinale [chukku] is triturated with leaf juice of Piper betle [Vettrilai] and applied in the eye for Glaucoma [10].

\subsection{Urinchal [Suction]}

Drainage of accumulated liquid such as pus, blood etc by suction. This technique is called Urinjal [3].

\subsection{Attai vidal [leech application]}

Leech application over affected areas of inflammation, blocks, etc. The leeches which are used therapeutically are not ordinary or dangerous ones. Hence the disease gets relieved. Leech application is usually done for hemorrhoids, contusions, swelling, tumours and ulcers. Leeches for this treatment should be maintained in healthy conditions in animal houses. To prevent cross infection, a separate set of leeches should be used for each patient [3].

\subsection{Kuruthi vangal [Venesuction]}

This is a process of bloodletting in the conditions where there is accumulation of toxic blood. In this type of treatment, a minor incision is made on the blood vessel and the excess blood is let out [3].

\subsection{Murichal [Bone restructuring]}

This is a method of physical manipulation in which bone setting is done to correct the dislocation of bones [3].

\section{$2.20 \quad$ Kombukattal [Fracture splinting/[mmobilisation]}

This comprises of immobilizing fractured bone using splints and bandages - after proper reduction. Fracture management is still a thriving practice among traditional bone setters all over the world. Skilled bone setters identify fractures by simple touch and bring the fracture ends to position by simple physical manipulation in a fraction of a second [3].

\subsection{Thokkanam [Physical manipulation]}

This treatment may be defined as physical manipulation of body or the massage treatment which is either given to the entire body or a particular diseased part. Massage is done in two ways: First is just by using bare hands and second by using oil. There are 9 techniques used in this treatment.

a.Thattal b. Irukkal c. Pidithal d. Murukal e. Kaikattal f. Azhuthal g. Izhuthal h. Malarthuthal i. Asaithal.

Thokkanam is a method of manipulation and mobilization used primarily in the treatment of conditions related changes in the varmam points leading to mechanical type of problems in joints and muscles [3].

\subsection{Podithimirdhal [Massage with dry powder]}

The procedure of this therapy is rubbing the herbal powders over diseased part or throughout the body. This massage procedure is done in upward directions only [3]. 
The equal quantity of Manjal [Curcuma longa], Kollu [Macrotyloma uniflorum], Chunnambu, Omam [Carum copticum], are gently fried, powdered and mixed with camphor powder. It is massaged over skin to treat Iyam related diseases [3].

\subsection{Vedhu [Steam therapy]}

Medicated steam exposure over the diseased part or throughout the body is termed as vedhu. The mechanism of Vedhu therapy is expelling out the wastes and impurities from the body via sweat glands.

Clerodendrum phlomidis [Thazhuthalai], Calotropis gigantea [Erukku], Vitex negundo [Notchi] leaves are stir fried and added to vinegar. The resultant vapour is applied to the body after oleation and massage to cure Vaatham diseases of the joints particularly rheumatoid arthritis [7].

\subsection{Pottanam [Medicated pouch]}

The raw herbs are ground and made into small pouches with bits of cotton cloth pieces. These medicated pouches are kept in the openings of the body like ear, nose and anus [3].

670 gms of Brassica nigra [kadugu] seed is taken in a cloth pouch with a string tied to its mouth. This pouch is soaked in warm Neem oil and after squeezing, the oil is pressed on the anterior fontanelle, posterior fontanelle, neck and the spinal joints for convulsive disorders and fever [12].

\subsection{Suttigai [Cautery]}

This is otherwise called heat application. This type of application is usually done over vertex, forehead, chest, back, hands and legs.

The 5 types of Suttigai are Kaanthi suttigaiSunbath, Kaatru suttigai- Exposure to blowing hot air, Mann suttigai- Suttigai with brick or earthen vessel, Mara suttigai- Suttigai with plant parts, Uloga suttigai- Metal cauterization ${ }_{[1]}$.

\subsection{Ottradam [Fomentation]}

Ottradam is the application of hot or cold packs. It is normally done with materials heated to appropriate temperature. While throwing out waste as toxins through the skin it also helps to disperse aggravated doshams, dilating all body channels for cleansing. Fomentation is classified into 2 types-hot and cold fomentations. It is the application of hot packs of pulses, cereals husk, lime, brick powder, leaves, etc. on or around the affected part for contusion and other swelling. Usually fomentation is used in Vaatham diseases. Equal quantity of the materials are crushed into a coarse powder and taken in a cloth bundle. This is saute with castor oil or medicated oil and fomentation is given [3].

Leaves of medicinal plants like Vitex negundo [Notchi], Calotropis gigantea [Erukku], Ricinus communis [Aamanakku], Abutilon indicum [Thuthi] etc are tied in a cloth as a bundle.

This medicated bundle is heated and applied over the affected area. This type of treatment is very effective for Vaatham ailments [Arthritis] and painful conditions like muscle cramps, bone disorders etc [3].

\subsection{Pugai [Fumigation]}

Fumigation denotes the artificial impregnation of the atmosphere, with the fumes or the smoke of any vegetable or aromatic substance. Fumes are also used for inhalation therapy. The process of fumigation with medicinal herbs under specific rituals influences widely the persons participating in it as well as the surrounding environment.

20.48 gms of charcoal of Calotropis gigantea [Erukku], 5.12 gms each of Mercuric sulphide [Lingam], Corrosive sublimate [Veeram] and Mercury [Rasam], 10.24 gms of Shorea robusta [Kungiliyam] are triturated together with roots of Achyranthes aspera [Naaiyuruvi] are made into seven pouches of a cloth soaked in the juice of Gossypium herbaceum [Paruthi]. The pouch is burnt with charcoal of tamarind twigs and the patient is exposed to the emanating fume. Fumigation is done for seven times. It cures 
Vaatham diseases like Crippling aches and Pain including Colic, restriction of joint movements [13].

\subsection{Aruvai [Excision]}

This is anatomical manipulation of any part of the using specific surgical instruments. The ideal time for surgical procedures is the morning. This is probably because that natural sunlight ensures precise treatment ${ }_{[3]}$.

\subsection{Kaaram [Chemical Cautery]}

It is the method of application of Medicated Caustic drugs over areas of excision or chronic ulcers [3].

$20 \mathrm{gms}$ each of Blue vitriol [Copper sulphate] and yellow orpiment [Aridhaaram] and $80 \mathrm{gms}$ of Shorea robusta [kungiliyam] are triturated with sesame oil, rinsed with fresh cool water and applied on a cotton cloth. This plaster is used to excise unwanted growth in external hemorrhoids, fistula, non-healing ulcers, granulomatous ulcers, abscess, toad skin and tumours with itching [14].

\subsection{Keeral [Incision]}

In this method, an incision is made over the boils, abscesses, carbuncles, acne, etc so as to drain the accumulated pus, blood, water, etc out of them. Incision of boils and removal of accumulated pus, blood, etc. The instrument used for this is called $\mathrm{Kombu}_{[3] \text {. }}$

\subsection{Salaagai [Probe]}

This is application of a probe which is a slender apparatus made up of a metal used to trace out fistulous tracks. This is an exploratory therapy using a probe which has blunt end. The probe is used in ophthalmic therapy particularly in the treatment of cataract. The probe is also used to explore deep seated abscess and introduce the medicated wick in fistula and sinus ulcer ${ }_{[14]}$.

\subsection{Peechu [Douche]}

Peechu is the external therapy in which herbal decoctions or medicines are allowed to pass forcefully through openings like anus and vagina, though this therapy is used as a cleansing method, it also acts as a medicine in curing the disease.

\section{Results and Discussion}

External medicinal applications are Gifts to Siddha, which need to be researched and practised with full concentration by all Siddha Doctors to make Siddha well flourished, welcomed and reached into the general population. It is our duty to expose our External therapy specialities like Varmam, Thokkanam, Kombu kattal, Vedhu, Pattru, etc. to modern world and other indigenous medicine world, so that the fame of siddha will be protected as well as propagated. It is very clear from the literature that the ancient physicians knew the connections between the brain and the sense organs and chose their routes and drugs accordingly. The physical therapies of Thokkanam, Varmam and most other therapies of Siddha are regaining popularity and efforts are on to validate and standardize the procedures. External therapies can be done in major measure with locally available resources and therefore is accessible as well as affordable.

\section{Conclusion}

This paper helps in giving Standard Operative Procedure towards Traditional therapies of Sidhha that have tremendous results in various diseases. The speciality of these Therapies lies therapeutic in nature. External therapies can be done in major measures with locally available resources and therefore is accessible as well as affordable to the entire society. 


\section{References}

[1] Thirunarayanan T. Introduction to Siddha Medicine, Chennai: Centre for Traditional Medicine and Research, 2012, 1-5.

[2] Thiyagarajan R, Gunapadam Thathu - Jeeva Vaguppu, Chennai: Directorate of India Medicine and Homoeopathy, $4^{\text {th }}$ edition, 1992, 35.

[3] Thirunarayanan T, Sudha R. External therapies of Siddha Medicine, Chennai: Centre for Traditional Medicine and Research, 2010, $5-25$

[4] Uthamarayan K S. Siddha Maruthuvanga Churukkam, Chennai: Department of India medicine and Homoeopathy, $3^{\text {rd }}$ edition, 2003, 45

[5] Ramachandran S P. Theraiyar Vaidhiyam 1000, Chennai: Thamarai Noolagam, $1^{\text {st }}$ edition, 1999, 27.

[6] Venkatarajan S. Sarenbendirar Vaithya Muraigal [Viranam, Karappan], Chennai: Thamarai Noolagam, $2^{\text {nd }}$ edition, 2004, 13-14.
[7] Pulippani Vaidhiyam 500, Central Research Institute for Siddha, Chennai 106, $1^{\text {st }}$ edition, 2009, 18-19.

[8] Kuppusamy Mudaliar K N. Siddha Vaidhiya Thirattu, Chennai: Department of Indian Medicine and Homoeopathy, $1^{\text {st }}$ edition, 1998, 41-42.

[9] Thiyagarajan R. Theraiyar Tharu, Chennai: Research Institute of Siddha, 1997, 20-21.

[10] Ramachandran S P. Theraiyar Vaidhiyam 1000, Chennai: Thamarai Noolagam, $1^{\text {st }}$ edition, 1999, 13-14.

[11] Ramachandran S P. Agasthiyar Ayulvedham 1200, Chennai: Thamarai Noolagam, $1^{\text {st }}$ edition, 1999, 17-18.

[12] Kandasamy Mudaliar. Athma ratchamirtham - Vaidhiya Sarasangiragam, Chennai: Sri Senbaga Pathippagam, $1^{\text {st }}$ edition, 2011, 35-36.

[13] Ramachandran S P. Agasthiyar Rana Vaidhiyam, Chennai: Thamarai Noolagam, $2^{\text {nd }}$ edition, 2000, 42-43.

[14] Uthamarayan K S. Siddhar Aruvai Maruthuvam, Chennai: Department of Indian medicine and Homoeopathy, $4^{\text {th }}$ edition, 2005, $17-18$.

\begin{tabular}{|c|l|}
\hline \multicolumn{2}{|c|}{ Access this Article in Online } \\
\hline 哭 & Website: \\
Quick Response Code & www.ijcrims.com \\
& Subject: \\
\hline Siddha Medicine \\
\hline
\end{tabular}

How to cite this article:

M.Nagalakshmi, S.Mohamed Ajmal, A.P.Uma. (2017). Exploration and Personification of External therapies in Siddha system of medicine. Int. J. Curr. Res. Med. Sci. 3(10): 4-10.

DOI: http://dx.doi.org/10.22192/ijcrms.2017.03.10.002 